\title{
Modern Development Tendencies of Ladle Vacuum Treatment
}

\author{
AV Protasov* and BA Sivak \\ Jshc Vniimetmash of academician Tselikov, Russia \\ *Corresponding author: AV Protasov, Jshc Vniimetmash of academician Tselikov, Russia
}

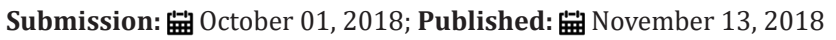

\section{Introduction}

Among famous methods of secondary steelmaking, vacuum treatment steel directly in the ladle so called, ladle vacuum treatment plays big role, there are a lot of different variations of technological process, however, the widest spreading got vacuum treatment by VD methods (vacuum degassing) or VOD methods (vacuum oxygen decarburization). Using oxygen blowing simultaneously with vacuum treatment gives ability getting special low-carbon steel (electric steel, stainless steel, automobile-body sheet with ability of deep extract, etc.). At last time combine equipment VD/VOD or VDOB (vacuum degassing - oxygen blowing) gets important spread. Comparative simplicity of construction and wide range of ladle vacuum units' technological abilities promote of their wide spread - around 65\% existing vacuum units are ladle type [1-3].

This tendency is most popular among new units: since 2000, more than 90 units for treatment of melts weight from $10-330 t$, have been produced or planned to start in nearest years, the biggest numbers of them are combined, providing going of classical processes VD and VOD on the separate or combined stands. During these processes, ladles with treated metal are directly covered vacuum-airtight lid (LD vacuum units - lid degassing) or (more often) are in the special vacuum chamber, covered by lid. Such types of vacuum units in modern special literature occur with name - (TD - tank degassing). However technological process going, achieved metallurgical results, the main properties and appearing problems, don't depend on working area airtight packing methods and ladle vacuum unit type. Both variations have proved their efficiency and using ability in practice, however tank vacuum units have got the widest spread. Using of airtight vacuum lids, installed on the ladle board flange, requires smooth safeguarding of connecting flanges from slag and metal scabs, that is hard realizing in industrial conditions.

Treated melts weight spread in limits 10-330t, however, the biggest number of ladle vacuum units are used for vacuum treatment of 30-150t melt weight (Figure 1), and located, in the main cases, in the electric steel-making shops. The wide spreading of ladle vacuum units is explained by their comparative simplicity, comfortable embeddedness into existing industrial conditions, wide range of technological abilities, including degassing, removing of nonmetallic components, efficiency multicomponent alloying with high precision of necessary chemical conditions achievement and high degree of alloying components adoption, deep steel decarburization and deculturation.

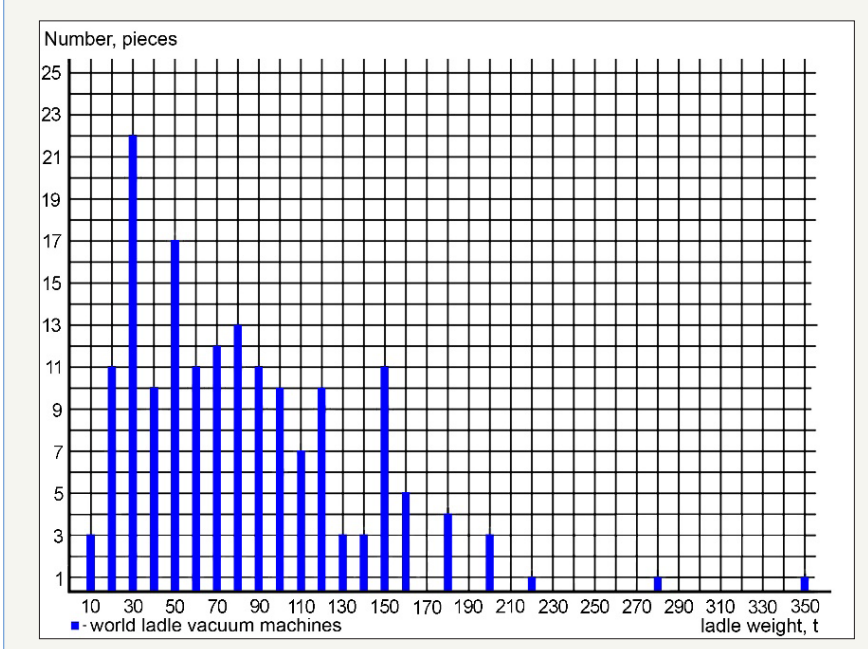

Figure 1: Ladle vacuum units spreading, built and planned to use since 2000 , by treated weight melt.

One example of ladle vacuum unit, using for heavy weight melts treatment more than 300t, is unit, which was installed in the Several company converter shop. For the mass using of ladle vacuum units in high productivity converter shops, there is a necessary to provide conditions for steel treatment intense, including exception of metal underfilling into the ladle, efficiency and uniform melt stirring. Essence of ladle refinement process consists in vacuum treatment, alloying under vacuum and treatment by synthetic slag from the surface metal, which is constantly renewed during gas-dynamic bath stirring by inert gas blowing (mainly by argon) through bottom tuner. Vacuum creation above surface melt metal and simultaneous argon blowing produce strong frothing and rising of metal and slag, which intensity depends on vacuum increase degree, its depth, argon consumption and metal oxidation degree. To protect of too big metal and slag combination increasing and going outside it through the casting ladle board, it is necessary to reduce vacuum increase degree and argon blowing intensity, and it is necessary 
to provide for free board ladle reserve above melt metal, which is much bigger in comparison with nominal volume of melt metal. During reach experience operation results of ladle vacuum units, there were produced average recommendations to choose height of free board reserve for different variations of technological process, independent from treated melt metal weight:

A. ladle vacuum treatment by VD-method - 0,8-1,0m;

B. oxidation vacuum treatment by VOD-method $-1,0-1,3 \mathrm{~m}$. (till 1,5m)

By some recommendations, free board reserve during VODprocess must be much more for tank vacuum units, and for vacuum units with airtight lid, supported on the ladle, it is purposeful to increase the reserve 20\% more [4]. This can be explained by, as it seems, more hard consequences of possible going out of metal through the ladle board, in comparison with tank type vacuum units. Increase of free board height might be achieved by increase common height of ladle or by reduce of metal weight in the ladle. In the first case, ladle weight and necessary casting crane lift capacity increase irrationally. In addition, higher ladle part, lifted above casting stand of continuous casting unit of billets, as a rule, determines common shop height, that's why during new shops building, serious additional capital cost is required. During adoption of the ladle vacuum treatment into existing steel making shops, such ability doesn't exist practically. In some cases, increase of ladle refractory weight, which is conclusion of adoption secondary steelmaking and using denser high-quality refractory materials, takes all existing reserves of cranes lift capacity.

Increase of free board height during simultaneous preservation of common ladle height and distance between journals, might be achieved by using oval form-section ladles or stair cylindrical form ladles [5] However, both variations jointed with more hard ladles and their refractory producing conditions. For the current productions, replacement of existing ladles is very expensive. That's why only one real way remains for providing reserve of free board in ladle vacuum units in existing productions - necessary reducing of metal weight in the ladle, which produces serious capacity losses of vacuum unit and the whole steel making shop, shows negative consequences on cost price and production competition ability. Especially visible reducing of comparative capacity can be noticed with less treated melt weight numbers. For example, according to the $375 \mathrm{t}$ ladle with necessary free board height 1,2-1,3m, [6] reducing of melt weight and capacity reducing are equal $12-15 \%$. And for the melt weight around 80t, metal underfilling, according to the same requirements to the free board, will be increased until 16-22\%. And among other things, ladle vacuum treatment is much more widespread with less than 100 t weight casting ladle productions.

It is important to notice, that any free board increasing doesn't give a guarantee of metal and slag splash exclusion with simultaneous increasing of vacuum speed degree and with serious increasing of argon consumption degree. In this case, the common vacuum treatment time during the ladle vacuum treatment, which is necessary for achieving proper results, and common treatment cycle time with preparing operations, are longer than the same results for the circulating vacuum units with the highest capacity. So, for example, comparison of two types units in the identical conditions in the electric steel-making shop of Belorussian metallurgical plant showed, that the full vacuum treatment process, using circulating vacuum unit (including necessary operations with ladle), goes 30-40min, and 50-70min, using VD-type vacuum unit [7].

The average time exceeding of vacuum treatment in existing VD/VOD-type units is around 5-8min in comparison with RH/ RH-OB-type vacuum units. According to this things, know about rapid increase of quantities continuous casting units for billets in our metallurgical plants, combine tendencies of union steelmaking, secondary steelmaking and continuous casting into union technological processes during increase of numbers serial casting melts, there is a very important necessity in the increase of ladle vacuum treatment efficiency and, first of all, in erasing necessity of metal underfilling into the ladle. There is one else negative moment of the ladle vacuum treatment, that refinement processes can be developed well only in comparatively thin active surface ladle zone, but power of natural technological stirring is not enough for the increase of lower metal. It is very important during the refinement processes to provide enough stirring of metal bath, because it improves kinetics of degassing processes and metal and slag cooperation.

During steel treatment with intensive decarburization (VODprocess), because of high temperature achieving, there are ladle border overheating problems and it is following deformation, which can be reasons for untimely ladle breakdown. Even without oxygen blowing, metal constructions temperature might grow up until $500^{\circ} \mathrm{C}$, it depends on metal level in the ladle. This problem is especially actual during production of special and stainless steel with long vacuum treatment cycle. The solution of this problem with compulsory cooling of the ladle border is very hard by technical conditions.

To resolute these pointed problems, principally new process VDF/VODF (Vacuum Oxygen Decarburization Full) was developed by specialists of VNIIMETMASH and Several company [8-11], which allows to reduce pointed negative factors and to increase ladle vacuum refinement efficiency. Vacuum unit is equipped by special reaction chamber with membrane, which is supported on the vacuum chamber flange. During the vacuum treatment, because of level gas-slag-metal emulsion increase, hydraulic gate is formed, which separates vacuum chamber parts on two zones with different vacuum degrees (I and II zones). As a result, increasing slag-metal emulsion, which certainly floods over the ladle during usual vacuum treatment technology VD/VOD of filled ladle, is limited in the additional reaction chamber.

The technological process is based on the principle of degassing metal volume localization, which is realized by installation of reaction chamber with separating inside area of vacuum chamber in two zones with different vacuum degrees, which allows to provide metal degassing exactly into reaction chamber space (Figure 2). Simultaneously, there are intensive metal circulation by 
directions 1-2-3-4 of chamber perimeter and refinement inside all ladle volume, which reduces treatment time.

Increase of gas-slag-metal foam goes only inside of reaction chamber, and absence of metal flood over the board are provided by hydraulic gate effect, which guaranties stable increasing vacuum level into zone II in comparison with zone I during degassing process.
Process and equipment were tested in the industrial conditions of converter shop Severstal company (Figure $3 \& 4$ ), where was increased vacuum treated melt weight from usual 320-325t till nominal $375 \mathrm{t}$. There was produced vacuum treatment of increased weight series melts, including decarburization and deculturation purposes. There were achieved necessary metallurgical results during reducing of vacuum treatment time $[11,12]$.
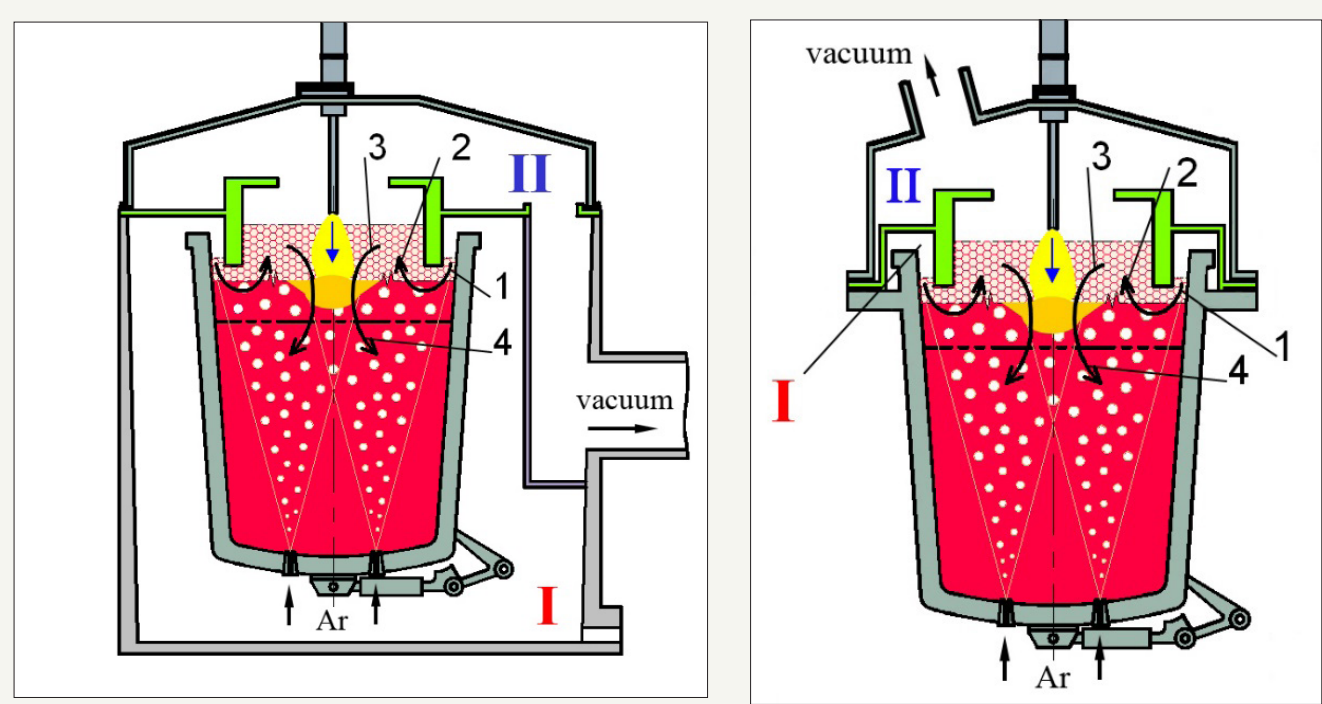

Figure 2: Principle scheme of VDF/VODF process: A-TD -variant; b -LD -variant.

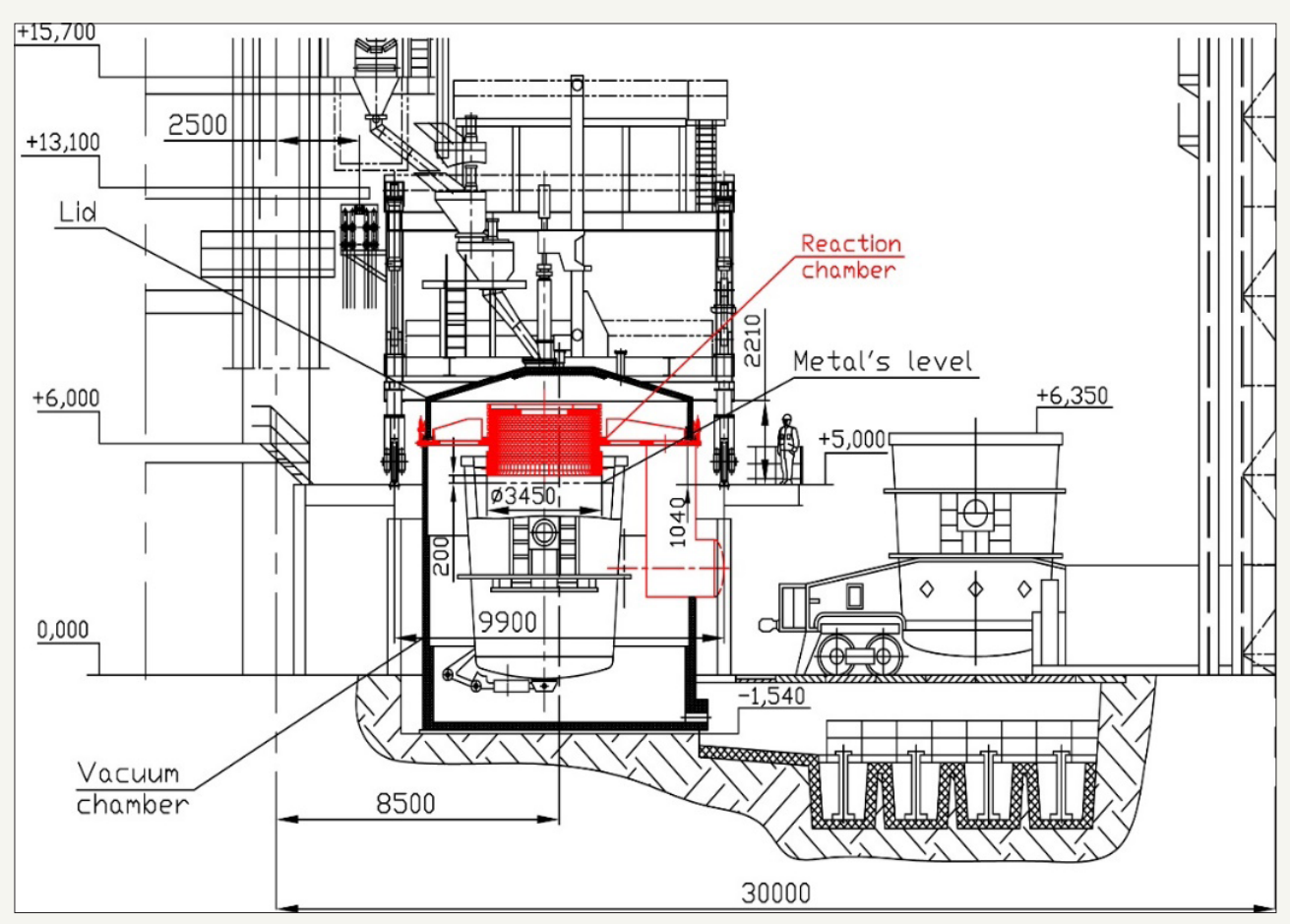

Figure 3: Modernized part of chamber type ladle vacuum unit located in Severstal company converter shop (375t ladle).

According to this, using new technological process, based on principle of degassing metal volume localization, allows to provide vacuum treatment of full melt for the less time. With guaranty of full melts treatment, the vacuum unit capacity increases average on $15-20 \%$ in comparison with the same VD/VOD-type unit and approaches to the RH/RH-OB-type unit capacity with more wide technological abilities (operation of desulphuration) and much less operational costs. 


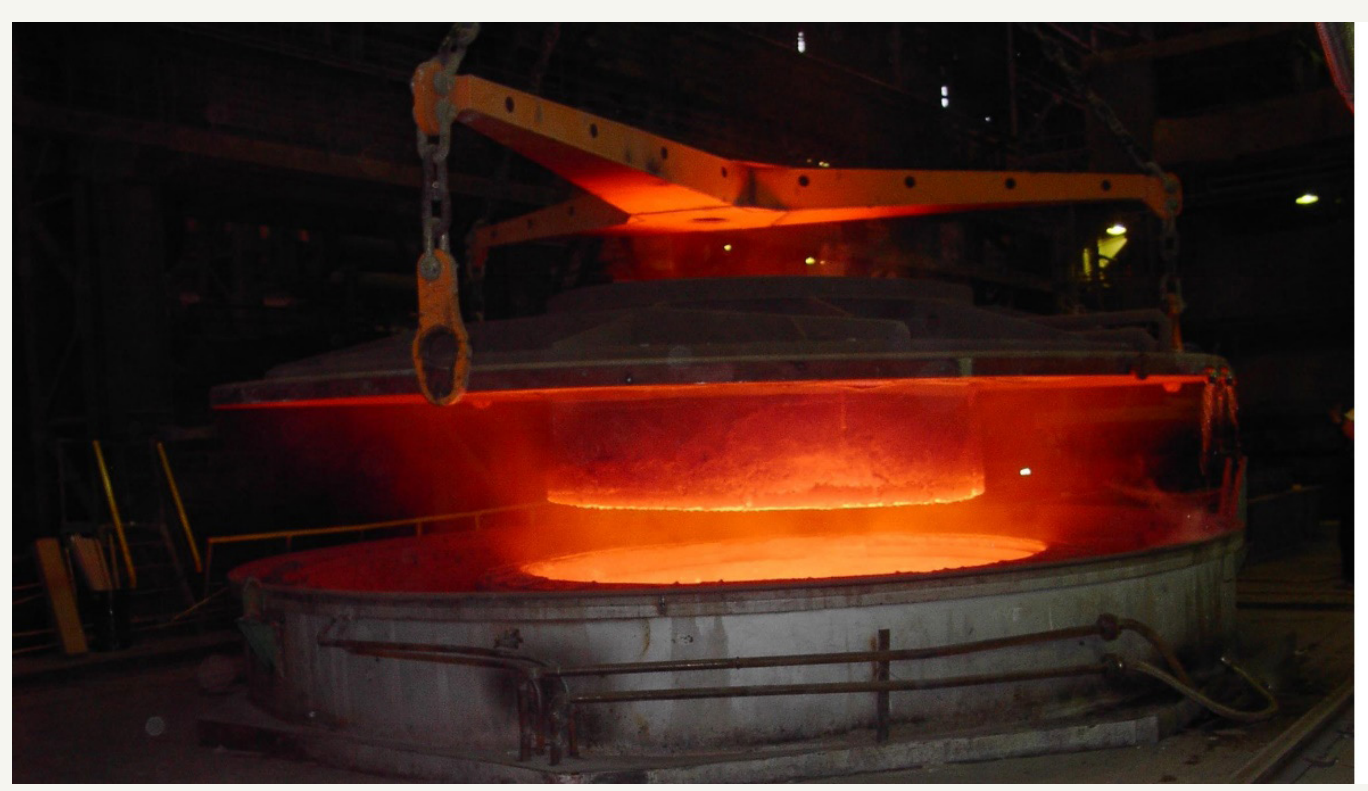

Figure 4: Installation of reaction chamber to the vacuum unit during industrial tastes.

Horizontal membrane in this equipment, which separates vacuum unit parts, allows to improve erasing slag dust and extraneous particles, because of most of them placed on the membrane surface and don't go inside again to ladle. Additional melt circulation between zones provides almost complete absence of scabs on the reaction chamber nozzle. A higher ladle board overheating in the case of oxygen blowing during decarburization with VODF-process is seriously reduced by high temperature zone protection, which is provided by reaction chamber nozzle and circulating melt.

Analysis of economic efficiency from technology and equipment adoption, during modernization existing VD/VOD-type units, shows that economic efficiency is combined by reducing self-cost of vacuum treatment $1 \mathrm{t}$ steel and increasing of its production with saving number melt. For the unit with year program about $1 \mathrm{mln} . \mathrm{t}$ (90130t ladle), cost increasing of vacuum treatment consists around $32 \mathrm{mln}$. roubles, and potential profit from production increasing of vacuum treated metal will exceed $2000 \mathrm{mln}$. roubles.

Pointed calculations show, that comparative economical wastes, because of liquid steel underfilling to ladle for the following traditional vacuum treatment by VD/VOD-technology, are equal $10-12 \%$ from the order volume for vacuum treated steel. During production of more expensive steel grades, for example stainless steel, comparative wastes will be higher. Modernization of existing vacuum treatment units, with independence from unit type, with reequip them to VDF/VODF-technology, is rather simple, doesn't require serious finance and time wastes and allows seriously increase economic efficiency of production. Doing of assembly works, balancing and commissioning by modernization is possible during plan repairs, without long time stops of equipment. Period of recoupment for modernization is no longer than 1 year.

The peculiarity of Russian economic system in current time is serious exceeding production abilities in comparison inside volume consumption. Development of Russian metallurgy has been in last time, in common cases, from the export trade of low added cost production.

Continuing finance crisis of world economic, rapid increase of China metallurgical industry and possible joining of Russia into the World Trade Organization don't give the reasons to expect to export increase. According to this information, there are no prerequisites for serious spread of metallurgical production in Russia, especially for input of new plants. Simultaneously, possible problems with production sale will require disbursement new hard and responsible steel grades, serious improving of production quality and reducing of production costs.

In these conditions, secondary steelmaking gets special importance, and the most dominate metallurgical development way, probably, will be plants modernization. Serious necessary in modernization of secondary steelmaking exists at foreign metallurgical plants, which have lots of ladle vacuum units, also there are a lot of outdated among them. That is why ability of quick, economical and effective parameters spread of existing ladle vacuum units, which might be based on VDF/VODF-process and equipment, has good perspectives for realization not only in Russia, but in many metallurgical plants of closer and farther foreign countries. It is very reasonable to use this technical solution during building new ladle vacuum units, because new ladle vacuum treatment process provides essential reducing of treatment time and its adoption into production process with serial casting of vacuum treated melts.

\section{References}

1. Protasov AV, Sivak BA, Chichenev NA (2009) Units and aggregates of metallurgical production: Aggregates of liquid secondary steelmaking, Lectures Course, M Publishing House, p. 182.

2. Protasov AV, Pasechnik NV, Sivak BA (2010) Equipment for secondary steelmaking, M Intermit Engineering, p. 415. 
3. Javani Ch (2003) Equipment and metallurgical aspects of vacuum treatment steel. Techint Technologies Melt Shops 9: 66.

4. ASM International (1988) Metals handbook, Casting, Fours printing, vol. 15.

5. Protasov AV (2003) Ladle for the secondary steelmaking, p. 28.

6. Efimov SV, Zinchenko SD, Filatov MV, Fomenko VA, Borodin DI (2004) Disbursement of IF-steel production with using of VD-OB-type ladle vacuum unit 7: 18-20.

7. Pivzaev VV, Anders VV, Gylyaev MP (2002) Comparative efficiency of steel degassing during vacuum treatment using RH and VD types vacuum units. Steel 10: 24-26.

8. Lukyanov AV, Schegolev AP, Sorokin AM (2008) Method of steel vacuum refinement in the ladle, equipment (variations) and nozzle for it working, p. 14
9. Lukyanov AV, Schegolev AP, Sorokin AM (2008) Improved process of steel ladle vacuum treatment. Steel 9: 15-19.

10. Schegolev NA, Lukyanov AV (2009) Peculiarity and preferences of steel ladle vacuum treatment by VDF/VODF-technology. Metallurgist 1: 50-52.

11. Lukyanov AV, Schegolev NA, Protasov AV, Sivak BA (2010) Industrial using outlooks of equipment and ladle vacuum refinement VDF/VODFtechnology of increased steel melts. Metals week in Moscow, pp. 283290.

12. Schegolev NA, Lukyanov AV (2009) Economic aspects of steel vacuum treatment by VDF/VODF-technology. Metallurgist 7: 44-46.

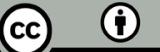

Creative Commons Attribution 4.0 International License

For possible submissions Click Here

\section{Submit Article}

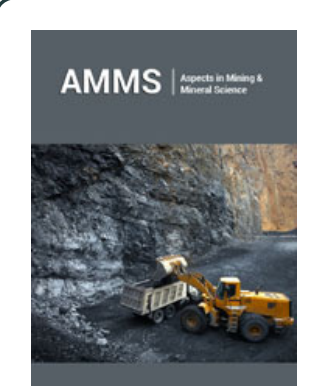

\section{Aspects in Mining \& Mineral Science Benefits of Publishing with us}

- High-level peer review and editorial services

- Freely accessible online immediately upon publication

- Authors retain the copyright to their work

- Licensing it under a Creative Commons license

- Visibility through different online platforms 